\title{
O direito fundamental a educação formal para o consumo como meio de concretização do direito a liberdade de escolha do consumidor e igualdade nas contratações e implementação do direito coletivo e social de proteção ao meio ambiente
}

The basic right to formal education for consumption as a mean of implementation of the consumer's freedom of choice and of equality in establishment of contracts as well as of the collective and social right to environment protection

\section{Edson Mitsuo Tiujo}

Universidade Estadual de Maringá, Brasil

\begin{abstract}
RESUMO Buscou-se, neste artigo, fundir dois direitos fundamentais - a defesa do consumidor e o direito a educação -, a fim concretizar a proteção de dois outros bens jurídicos, quais sejam: a liberdade de escolha do consumidor e a igualdade nas contratações, bem como a proteção ao meio ambiente. Propôs-se, em seguida, a elaboração de uma política pública de educação formal para o consumo, levando-se em consideração inúmeros fatos sociais, políticos e econômicos que se verificam no dia-a-dia e que distorcem a racionalidade do consumidor, como as práticas comerciais de angariamento de consumidores, as políticas econômicas de incentivo ao consumo e a política educacional despreocupada com o desenvolvimento do poder de reflexão e juízo crítico do cidadão. Objetivou-se, ao final, definir a competência institucional para a elaboração dessa disciplina curricular, bem como o formato jurídico-político para sua concretização.
\end{abstract}

PALAVRAS-CHAVES Direitos fundamentais; Defesa do consumidor; Proteção ao meio ambiente; Educação formal; Currículo escolar.

ABSTRACT The objective of this paper is to discuss the convergence of two basic rights - to consumers protection and to education - which aim to implement others, namelly freedom of choice of the consumer and the rights to contractual equality as well as environment protection. The article proposes the formulation of a formal education to consumption public policy taking into account countless daily social, political and economic facts that distorts consumers rational choice as commercial practices of consum- 
ers recruitment, economic policies of consumption stimulation and a educational policy unconcerned with the development of citizens power of reflection and critical judgement. The final part of the text aims at defining the institutional competence to develop that curricula as well as the legal framework for its implementation.

KEYWORDS Fundamental rights; Consumer protection laws; Environmental protection; Formal education; School curriculum.

\section{Introdução}

$\mathrm{O}$ presente artigo deverá fundir dois direitos fundamentais, sendo um, o direito a defesa do consumidor (art. $5^{\circ}$, XXXII) e, o outro, o direito social a educação (art. $6^{\circ}$ ), para, ao final, buscar garantir a integral liberdade de escolha e igualdade nas contratações dos cidadãos participantes do mercado de consumo e, simultaneamente, a proteção ao meio ambiente como bem jurídico social e coletivo. Da fusão desses direitos fundamentais, propôs-se a elaboração de uma política pública de educação formal para o consumo, por meio da criação de uma disciplina para o ensino fundamental da Educação Básica, objetivando o pleno exercício da cidadania pelo consumidor e a garantia da preservação do meio ambiente para as presentes e futuras gerações.

A par da notável utilidade dessa prestação pública, é certo que a sua instituição, ainda gera muitos debates e oposições. Por meio deste artigo, pretende-se debater alguns desses conflitos, propondo-se, para tanto, o desenvolvimento do trabalho em quatro tópicos.

O primeiro capítulo, ainda que breve, será necessário para compreender a estrutura bidimensional dos direitos fundamentais e sua característica da multifuncionalidade (Nogueira, 2008; Salazar, 2016; Biglino, 2017; de Mello, 2015; Aleix, 2013; Fuertes-Planas, 2013; Gonzalez,2012; Gómez, 2014; Lopez, 2014; Prado, 2017; Rodríguez, 2017). Neste capítulo, demonstrar-se-á que os direitos fundamentais estão submetidos a um regime especial, o qual investe o cidadão de uma posição jurídica de vantagem frente a tais direitos e, simultaneamente, impõe ao Estado o cumprimento espontâneo de um dever correspondente a esse mesmo direito. Somente a partir dessas noções elementares é que será possível compreender o fundamento para o conteúdo e objetivos da proposta de política social que ora se faz.

O segundo capítulo, por conseguinte, será voltado a discutir a função prestacional normativa dos direitos fundamentais, principalmente, por meio da elaboração de políticas públicas. O capítulo exporá, ainda, os objetivos das políticas públicas e a complexidade para sua implantação, visando, sobretudo, a promoção da dignidade humana em seu grau máximo. É nessa esteira, que se apresentará nesse capítulo, os primeiros argumentos para viabilidade da implantação da educação para o consumo, como disciplina integrante da base curricular. 
O terceiro capítulo apresentará a dupla matriz constitucional da defesa do consumidor - direito fundamental e princípio econômico - e as consequências da sua previsão ao lado de outros princípios aparentemente conflitantes, como a livre-iniciativa, a propriedade privada e a livre-concorrência. Esses princípios aparentemente conflitantes, particularmente no que se refere à relação de consumo, pode resultar em uma proteção insuficiente do consumidor, limitada apenas a coibição da ilicitude e da abusividade, não abarcando uma tutela preventiva, exigível diante dos vários fatores sociais, políticos e econômicos que, marcadamente, massacram o cidadão no dia-a-dia do mercado. Ainda, este terceiro capítulo, destinar-se-á a traçar o conteúdo dessa disciplina que se pretende implantar no currículo escolar, a partir de objetivos voltados essencialmente a incutir no consumidor o poder de reflexão e o juízo crítico.

Após a apresentação dos fundamentos dessa política pública e os argumentos para sua implantação, o quarto capítulo tratará da formalização da educação para o consumo como matéria do currículo mínimo do ensino fundamental. Para tanto, a investigação estará voltada a verificação da competência institucional-normativa para a implementação da matéria em âmbito nacional e a identificação do instrumento jurídico-político para a sua implementação. (Ilera, 2017;Embid, 2008; Montoya, 2010; Pérez Perdomo, 2018; Flores, 2014; Elgueta, Palma, 2014)

\section{A estrutura normativa bidimensional dos direitos fundamentais e a característica da multifuncionalidade: uma base para viabilizar a discussão}

A Constituição da República Federativa do Brasil (CRFB) reconhece, em diversos enunciados normativos, o direito a educação (arts. $6^{\circ}, 22$, XXIV, 24, IX e 205 a 214). A partir do reconhecimento deste direito, o cidadão está investido em uma série de posições jurídicas de vantagem, que o permite exigir do Poder Público, o seu direito de ser educado para o desenvolvimento, o trabalho e o exercício da cidadania. O Estado, por sua vez, independentemente, da postulação do cidadão, tem o dever de garantir, espontaneamente, a toda coletividade os benefícios relacionados a esse direito social, os quais encontram-se enumerados nos textos dos artigos acima citados.

Mas, de imediato, surgem as questões: qual o fundamento dessa posição jurídica de vantagem do cidadão frente ao Estado? E, por que o Poder Público tem a obrigação de garantir tais direitos de educação ao cidadão?

A resposta a esta indagação está no advento do Estado Social e Democrático de Direito que, por sua vez, tem por fundamento precípuo a garantia de direitos fundamentais aos seus cidadãos. De modo sucinto, os direitos fundamentais são um conjunto de direitos - individuais ou de liberdade, coletivos, sociais (Novais,2010:17), políticos, culturais e de nacionalidade -, configurados como categoria jurídica autônoma, já que submetidos a um regime jurídico especial (Hachem,2013; Novais, 2010), tendo por fundamento a dignidade da pessoa humana (Netto,2009), haja vista 
que indispensáveis a vivência e sobrevivência dos cidadãos, que se encontram em posição jurídica de vantagem frente ao Estado, ao qual é atribuído uma multiplicidade de funções - defensiva, protetiva e prestacional - e que também podem ser direcionados a outros sujeitos privados (Sarlet, 2007).

Nesse primeiro momento, o aspecto mais relevante dessa breve definição de direitos fundamentais é, indiscutivelmente, o seu regime jurídico diferenciado. É esse regime que distingue as normas de direitos fundamentais daquelas que, no Direito Privado, outorgam direitos subjetivos aos seus destinatários (Hachem, 2013) ${ }^{1}$. É, ainda, esse regime especial que permitirá justificar e fundamentar a proposta do presente artigo, qual seja, a elaboração de uma política de educação para o consumo, direcionada a ensino fundamental ${ }^{2}$, tendo em vista a concretização integral do direito fundamental de defesa do consumidor, por meio da garantia da sua ampla liberdade de atuação no mercado de consumo, bem como a implementação de outros direitos fundamentais sociais e coletivos, pela conscientização do consumo e consequente proteção ao meio ambiente.

Nesse estudo, propõem-se que, (a) de um lado, o consumidor possa sindicar o seu direito de liberdade de atuação no mercado de consumo, contra as práticas abusivas dos fornecedores e as políticas econômicas estatais de incentivo ao consumo e; (b) de outro lado, o Poder Público possa elaborar uma política pública de educação formal para o consumo voltada a toda a sociedade, tendo em vista não apenas a prevenção dos consumidores contra tais armadilhas, mas também a proteção ao meio ambiente, por meio do consumo consciente.

Mas, diante dessas proposições, indaga-se: o que justifica o direito a reivindicação do cidadão a essa proteção da sua liberdade de atuação no mercado de consumo? E, o que fundamenta o dever de prestação normativa do Estado a elaboração dessa política de educação?

A resposta a essa pergunta está baseada, justamente, no regime especial das normas de direitos fundamentais que revela, em sua radiografia, uma estrutura normativa bidimensional e, em seu conteúdo, multifárias pretensões jurídicas e múltiplas funções estatais. Daniel Wunder Hachem (2013:627) explica a estrutura bidimensio-

1. Sobre isso, explica Daniel Wunder Hachem: «A lógica de sua aplicação, por consequência, seguiria a mesma sorte que presidia a racionalidade próprio do modelo forjado no século XIX: descumprida a obrigação e afetada a situação jurídica de vantagem do titular do direito, a este (sujeito individual determinado) caberia a propositura da ação judicial correspondente. Sendo, assim, nos casos de violação, tudo seria simples. Qualquer inobservância aos deveres impostos pelas normas de direitos fundamentais seria passível de correção pelo Poder Público» (A dupla titularidade ... Op. Cit., p. 627).

2. O Sistema Educacional Brasileiro é constituído por dois níveis (art. 21 da LDBE): (a) Educação básica; e, (b) Educação superior. O primeiro nível, por sua vez, é composto por três etapas: (a) educação infantil (crianças de até 6 anos de idade); (b) ensino fundamental (crianças e adolescentes dos 7 até os 15 anos); e, (c) ensino médio (adolescentes de 16 a 18 anos). 
nal das normas de direitos fundamentais, expondo que, embora a arquitetura dos enunciados normativos - notadamente de direitos subjetivos - possa parecer similar, a estrutura jurídica das normas de direitos fundamentais, derivada da construção resultante de uma interpretação sistemática de tais enunciados, ostenta uma engenharia diferenciada que as caracteriza e distingue das demais. Enquanto os enunciados normativos de direitos subjetivos podem ser visualizadas apenas em uma única perspectiva, as normas de direitos fundamentais podem ser vistas sob duas óticas distintas: subjetiva e objetiva.

Na ótica subjetiva - ou seja, na visão do titular do direito ou bem jurídico que ela pretende proteger -, os direitos fundamentais se afiguram como um feixe de posições jurídicas de vantagem (Novais, 2010) em favor de um cidadão individualmente considerado. Nessa perspectiva, Estado e cidadão se posicionam numa nítida relação bilateral, da qual pode exsurgir, em caso de não cumprimento da norma de direito fundamental, uma pretensão individual juridicamente reforçada com a correspondente judiciabilidade (Novais, 2010:96).

Por outro lado, na ótica objetiva - ou seja, na perspectiva do objeto que ela visa a proteger - a norma de direito fundamental faz surgir para o Estado um feixe de deveres jurídicos para com os cidadãos de variados fins (defensivos e prestacionais), impondo-lhe diversas obrigações expressas ou implícitas para salvaguarda do direito fundamental (Hachem, 2013:630), os quais devem ser realizados espontaneamente pelo Poder Público.

Quer isto dizer que, das normas de direitos fundamentais, mesmo daquelas que preveem primariamente posições jurídicas subjetivas, é possível extrair conteúdos jurídicos não-subjetivizados - ou seja, que vão além da sua dimensão subjetiva -, que ultrapassam a estrita relação Estado / indivíduo, para admitirem uma validade universal e objetiva de valores que legitimam a ordem jurídico-constitucional do Estado (Novais, 2010:57-58) a agir na implementação espontânea, integral e igualitária dos direitos fundamentais.

A partir dessa característica da dupla dimensão, portanto, exsurge outro efeito dos direitos fundamentais, consistentes em diversas e complexas funções, efeito este a que se chama de multifuncionalidade das normas de direitos fundamentais. Essa característica, por sua vez, representa os vários papéis que o Estado tem a desempenhar para que os cidadãos possam viver dignamente. Significa dizer que os direitos fundamentais não podem ser associados a uma função única, mas sim a variados deveres - de respeito, proteção e prestação (fática e normativa) (Alexy, 2015) -, os quais são imprescindíveis para a plena implementação e concretização da vida digna do cidadão.

Sem o intuito de tentar explanar sobre as múltiplas funções dos direitos fundamentais, é da função de prestação normativa, oriunda da dimensão objetiva dos direitos fundamentais, que se pode cogitar da elaboração de uma política pública de 
educação formal para o consumo, com vistas não apenas a garantir o exercício da cidadania pela plena liberdade de atuação do consumidor no mercado de consumo, mas também assegurar a proteção ao meio ambiente como bem jurídico de toda coletividade e necessário à vida digna das futuras gerações.

Feitas tais considerações, o presente artigo se projetará a partir de agora no desenvolvimento do estudo da função prestacional normativa do direito fundamental à educação, tendo como objeto a defesa e promoção do consumidor e do meio ambiente.

\section{A função prestacional normativa dos direitos fundamentais, por meio de políticas públicas sociais tendentes a promover a dignidade humana em seu grau máximo}

Para que os direitos fundamentais possam ser gozados em sua integralidade, tais direitos pressupõem atuações do Legislador e da Administração Pública, no sentido de viabilizar a universalização do seu exercício por todos os cidadãos, pela proteção contra as investidas do ente público e outros entes privados e, também, na medida do possível, pela prestação material e normativa tendente a propiciar melhor qualidade de vida aos cidadãos (Hachem,2013:639).

Esses desideratos somente são viabilizados por causa da função prestacional normativa decorrente da feição objetiva dos direitos fundamentais. As prestações normativas são, ao mesmo tempo, dever do Estado e direito do cidadão à elaboração de normas por todos os Poderes Públicos, «necessárias à proteção de determinados bens jurídicos (função de proteção) ou à criação de organizações e procedimentos que auxiliem na promoção e na proteção dos direitos fundamentais (função de organização e procedimento)» (Hachem, 2013:520).

No que se refere ao direito à educação, a CRFB foi bastante exaustiva ao consagrálo, disciplinando amplo acesso a esse bem jurídico, por meio dos arts. $6^{\circ}, 22, \mathrm{XXIV}$, 24, IX e 205 a 214. Da mesma forma, a legislação infraconstitucional, por meio da Lei n. 9.394/1996 (Lei de Diretrizes e Bases da Educação - LDBE), também assegurou a contento a política educacional, pelo menos, em nível de Educação Básica (infantil, fundamental e médio), sendo as avaliações quantitativas bastante satisfatórias, especialmente, a partir da década de 1990.

Contudo, a questão que se coloca, nesse momento, é: é conveniente a elaboração de uma política pública para a criação de uma disciplina na Educação Básica - notadamente no ensino fundamental -, direcionada a educação do jovem cidadão para o consumo?

O debate é pertinente e oportuno, porque as políticas públicas envolvem sempre uma conotação valorativa e causam profundas discussões quanto à sua instituição, exigindo sempre uma análise interdisciplinar relacionada a outros subsistemas (Fa- 
ria, 2009:159), bem como a apreciação cautelosa das suas etapas sequenciais de processualização (Valle,2009:40-41) .

As políticas públicas, assim, se afiguram como um programa de ação governamental (Bucci, 2006:252), envolvendo todos os seus níveis (federal, estadual e municipal) (Valle, 2009:37), instituído por meio de um processo regulado, mediante a observância dos meios à disposição do Estado, voltados à realização de objetivos socialmente relevantes e politicamente determinados (Barcellos, 2008:102) e sua continuidade por meio de ações subsequentes de apoio e avaliação (Valle,2009:37), para garantir à coletividade, por meio de cada cidadão, condições mínimas de existência digna e condições suficientes para que cada pessoa possa desenvolver livremente a sua personalidade (Gabardo, 2009:331).

Pois bem. Quando se fala na elaboração de uma política social, quer-se dois objetivos precípuos: (a) primeiro, corrigir problemas sociais que atrapalhem a proteção e promoção adequada dos direitos fundamentais e que impeçam indivíduos e setores específicos da sociedade de lograr acesso igualitário aos bens jurídicos por ele protegidos, e (b) segundo, garantir a promoção da dignidade do cidadão em seu grau máximo, mesmo porque a satisfação do conteúdo integral dos direitos sociais não se limita apenas ao atendimento ao mínimo existencial.

O estudo ora proposto parece propício a cumprir com esses dois objetivos. Em primeiro lugar, porque as políticas econômicas voltadas ao incentivo ao consumo e as práticas comerciais direcionadas ao cidadão, embora, não sejam efetivamente um problema social, podem trazer uma drástica consequência social, especialmente, em relação ao consumo supérfluo e exagerado, causadores, por sua vez, do superendividamento e da escassez de recursos por desperdícios. Em segundo lugar, porque a concretização dos dois direitos fundamentais ora propostos, por meio de uma política pública tendente a maximizar a dignidade humana, poderá permitir não apenas a plena liberdade de atuação do consumidor no mercado de consumo, como também a maior proteção do meio ambiente como bem jurídico social e coletivo.

As justificativas acima expostas serão abordadas e aprofundadas no próximo tópico. É fato, no entanto, que a proposta que ora se defende deve ser concretizada mediante uma política pública para o serviço público (Hachem,2013:520 $)^{4}$, direcionada

3. Vanice Regina Lírio do Valle enumera as etapas sequenciais de implementação de uma política pública, como: (a) o reconhecimento do problema; (b) a formação da agenda; (c) a formulação da política pública; (d) a escolha da política pública a ser implementada; (e) a implementação da política pública eleita; e, (f) a análise e avaliação da política pública executada.

4. A Administração Pública pode concretizar os direitos fundamentais de diversas formas: (a) por meio de um regulamento administrativo que discipline normativamente meios de acesso àquele bem jurídico jusfundamental; (b) por meio de um serviço público que forneça prestações materiais necessárias à fruição do direito; e, (c) mediante políticas públicas que ampliem o grau de satisfação de determinado direito fundamental e corrijam problemas sociais e econômicos. 
a maximização dos direitos fundamentais à educação e à defesa do consumidor, como forma de permitir o pleno exercício da cidadania. Nesse contexto, defende-se que o serviço público é apenas um meio para se implementar a política pública e, consequentemente, atingir a máxima concretização dos direitos fundamentais sociais.

Tecidas essas considerações, outra questão que se coloca, é: qual o formato jurídico-normativo para a implementação da política pública, notadamente, em relação a elaboração de uma nova disciplina nos currículos da Educação Básica?

Deveras, as políticas públicas podem ser veiculadas por várias espécies de instrumento normativo. Daniel Wunder Hachem (2013:522) explica que as políticas públicas podem ser instituídas por diversas formas jurídico-normativas, podendo ser encontradas em sede constitucional, em atuação do legislador infraconstitucional e, ainda, em criação direta da Administração Pública (decretos e portarias e até mesmo em instrumentos jurídicos de outra natureza, como contratos de concessão de serviço público) (Bucci, 2006:11) - embora sempre inspiradas nos programas de ação política assegurados constitucionalmente -, ainda que inexistentes fundamento legal específico que determine a implementação daquela política.

A par da variabilidade das formas jurídicas para elaboração e implementação das políticas públicas, o último tópico deste artigo destinar-se-á a discutir o modo de formalização dessa política pública, especialmente, no que se refere a competência institucional-normativa para a implementação da disciplina de educação formal para o consumo, bem como os instrumentos legais para tal implementação.

\section{O direito a educação formal para o consumo como meio de concretizar o direito a liberdade de escolha do consumidor e igualdade nas contratações no mercado de consumo e implementar o direito coletivo e social de proteção ao meio ambiente}

\section{A política pública de educação para o consumo como direito básico do consumidor}

A defesa do consumidor é, na ótica da CRFB, um direito fundamental de liberdade (art. $5^{\circ}, \mathrm{XXXII)} \mathrm{e,} \mathrm{ao} \mathrm{mesmo} \mathrm{tempo,} \mathrm{um} \mathrm{princípio} \mathrm{da} \mathrm{ordem} \mathrm{econômica} \mathrm{(art.} \mathrm{170,}$ V). Essa dupla matriz constitucional mostra a importância que o Poder Constituinte Originário deu ao cidadão-consumidor como elemento integrante do mercado de consumo. Esse reconhecimento constitucional, por si só, justifica a realização de qualquer política pública, tendente a corrigir problemas sociais e maximizar a satisfação do seu conteúdo, permitindo ao cidadão usufruí-lo em seu grau máximo.

Portanto, não é preciso reconhecer caráter social aos direitos fundamentais - notadamente, à defesa do consumidor e à educação - para garantir-lhes a formação de políticas públicas, uma vez que todos os direitos fundamentais, indistintamente, 
estão sujeitos ao mesmo regime jurídico especial. É salutar reconhecer, contudo, que a proteção concebida pelo legislador infraconstitucional à defesa do consumidor, por ocasião da elaboração do CDC, é bem mais ampla, é difusa, coletiva (Silva,2014:548) e nitidamente social (OCDC), o que lhe garante um viés de proteção totalmente distinto.

O que se questiona e se propõe neste artigo, todavia, é se a intervenção estatal preconizada para a proteção do consumidor é realizada de forma plena e suficiente, de modo a garantir não somente a proteção do cidadão, como também a sua ampla liberdade de atuação no mercado de consumo. A indagação que se coloca é salutar, na medida em que a defesa do consumidor, no âmbito constitucional, é enumerada ao lado de outros princípios aparentemente com ela conflitantes, como a livre-iniciativa, a propriedade privada e a livre-concorrência.

Esse rol aparentemente conflitante de princípios da ordem econômica, pelo que se constata, resultou em uma proteção apenas parcial e, portanto, insuficiente do consumidor e da sua liberdade de atuação. Isso porque, a necessidade de convivência desses princípios levou a adoção do vetusto argumento: «o direito de cada um termina onde começa o do outro». A interpretação desse embate foi e é no sentido de que o fornecedor tem ampla liberdade de explorar a relação e o mercado de consumo, desde que não afete a esfera de direitos do consumidor. Sem o intuito de criticar a CRFB, esse argumento transposto para a realidade fática e jurídica, teve o condão de atuar, preponderantemente, na coibição da ilicitude e abusividade, o que se verifica nitidamente por meio do reconhecimento legal das práticas abusivas (art. 39 do CDC), cláusulas abusivas (art. 51 do CDC), publicidades abusivas (art. $37, \$ 2^{\circ}$ do CDC), cobranças abusivas de dívida (art. 42, caput do CDC) etc.

A partir dessas considerações, propõe-se a seguinte questão: é possível, plausível e necessário ampliar ainda mais a proteção do consumidor - de forma preventiva -, por meio da sua educação e informação, especialmente, no âmbito escolar?

Pensa-se que sim. E existe viabilidade para tanto. Fatos sociais e viabilidade jurídica, constitucional e infraconstitucional, autorizam a elaboração dessa política pública, tornando-a necessária e útil do ponto de vista social, justa do ponto de vista econômico e plausível do ponto de vista jurídico.

A intervenção estatal para proteção e promoção do consumidor, portanto, deve ir além da coibição de ilicitudes e abusividades. Esse modo de proteção concentra a defesa do consumidor basicamente nas chamadas fases contratual e pós-contratual da relação de consumo. Por outro lado, ainda que não esteja totalmente desprotegido - especialmente, por conta da regulamentação das formas de oferta e publicidade -, o consumidor não é efetivamente protegido na chamada fase pré-contratual, ocasião em que poderia ser tutelado preventivamente contra as armadilhas do mercado de consumo e os malefícios do consumo supérfluo e exagerado.

Diversos outros fatos podem ser citados para justificar a necessidade da educação 
formal do consumidor, como: (a) as práticas comerciais cada vez mais bem elaboradas e ocultas, inclusive, com o auxílio das redes sociais, além do preparo técnico e diálogo comercial dos fornecedores, para vender seus produtos e serviços; (b) a participação efetiva e direta das crianças e adolescentes, como influenciadores e influenciados, na aquisição de produtos e serviços para as famílias; (c) as políticas econômicas de incentivo ao consumo, com o intuito de alavancar a econômica de mercado, mormente, em épocas de crise e em países de economia crescente como é a brasileira; (d) a política educacional ineficiente e voltada para o desenvolvimento de competências típicas para o trabalho e o consumo no mercado, sem se preocupar com o desenvolvimento do poder de reflexão do estudante (Maues, 2009:287).

Pois bem. Relatados os problemas sociais e econômicos decorrentes da carência de reflexão do consumidor na relação e no mercado de consumo, outro aspecto a ser ressaltado, diz respeito a conveniência jurídica para a criação da disciplina de educação formal para o consumo. E, neste particular, as determinações, constitucional e infraconstitucional, dão total fundamento para a viabilidade e possibilidade dessa política pública.

$\mathrm{O}$ art. 205 da CRFB indica como perspectivas da educação para o cidadão, além do (a) pleno desenvolvimento da pessoa e (b) de sua qualificação para o trabalho, também (c) o seu preparo para o exercício da cidadania. Quer isto dizer que, a educação não se limita apenas a alfabetização do cidadão - pela possibilidade da leitura, da escrita e do cálculo - e a sua capacitação para o trabalho, mas também e principalmente a promover a autonomia do indivíduo, a sua visão de mundo, o seu aperfeiçoamento humanístico, o seu sentimento de responsabilidade para com o mundo em que vive, as suas responsabilidades cívicas e sua consciência pelo valor dos direitos individuais e sociais (Maliska, 2014:1965).

Esse direito fundamental a educação para a cidadania foi incorporada pelo legislador infraconstitucional, estando prevista no inciso II, do art. $6^{\circ}$ do CDC. E, uma vez incorporada, não se pode omitir a sua concretização, haja vista que as leis cujos conteúdos densificam as normas constitucionais de direitos fundamentais ampliam a sua eficácia, permitindo a sua máxima efetividade (Shier, 2016:205), além do que, são de aplicabilidade imediata ( $\operatorname{art.} 5^{\circ}, \$ 1^{\circ}$ da CRFB) e protegem o cidadão contra a inércia dos Poderes Públicos (Hachem,2013:130).

Apenas para encerrar a discussão deste tópico, pensa-se que, a criação da política pública ora proposta, no atual contexto, é bastante oportuna. Representaria, deveras, um salto de qualidade na educação brasileira, mesmo para aqueles que defendem a implementação dos direitos sociais de maneira progressiva (Sgarbossa, 2010:129133)5. Aliás, principalmente, para estes, pois é inegável que a implementação quanti-

5. Explica que, o argumento da implementação progressiva dos direitos sociais surgiu após a Segunda Guerra Mundial, levantada pelos países ocidentais capitalistas, notadamente, por ocasião da deliberação 
tativa desses direitos já foi promovida no Brasil, notadamente, em relação ao direito a educação em nível básico; agora, a implementação deve ser promovida em termos qualitativos.

Desde a CRFB de 1988, muito já se conquistou em termos de direitos sociais. Jorge Abrahão de Castro (2011:88-89), em artigo sobre a análise e avaliação das políticas sociais, apresenta, em dados estatísticos, todos os custos e benefícios decorrentes dessas prestações públicas. Em referido trabalho, o autor demonstra toda a evolução ocorrida nos diversos setores dos direitos sociais, desde o aparato institucional até os benefícios criados e as pessoas beneficiadas. Para se ter uma ideia, até 2007, ano em que as pesquisas foram realizadas, a taxa de frequência à escola das crianças e jovens de 7 (sete) a 14 (quatorze) anos já havia atingido, impressionantes, 98\% (noventa e oito por cento), tendo aumentado, ainda, o número de anos de permanência dos alunos na escola e a considerável queda do analfabetismo.

Pois bem. Ainda que a implementação progressiva dos direitos sociais seja discutível entre os estudiosos dos Direitos Fundamentais, o fato é que, as políticas sociais na área da educação já atingiram patamares consideráveis, não sendo inoportuno, a criação de outras políticas sociais para a qualificação da educação. Quer se defender, com isso, que a promoção dos direitos sociais - notadamente no campo da educação - sempre terá espaço, nunca sendo de mais, o início de mais um ciclo de políticas públicas.

Feitas as considerações acerca da factibilidade social, política e jurídica da educação formal para o consumo como direito básico do consumidor, o próximo tópico destinar-se-á a apresentar o conteúdo e os objetivos dessa política pública.

\section{O conteúdo da disciplina e os objetivos da política pública de educação para o consumo}

Deveras, o preparo do cidadão para o exercício da cidadania - um dos objetivos constitucionais da educação - não pode servir como argumento para a criação de um sem número de disciplinas escolares de conteúdos sociais ou morais (Aizpurua et al 2018; Aristizabal-Almanza,2018; Briede, 2018; Ganga et al, 2013; Hernández et al, 2017; Gonzalez, 2013; Jimenez et al, 2018)

A educadora e cientista política Rosimar de Fátima Oliveira (Oliveira, 2009:164) chama atenção para os parlamentares oportunistas que, com esse discurso, propõe

dos Pactos Internacionais dos Direitos Civis e Políticos e dos Direitos Econômicos, Sociais e Culturais, em 1966. O temor manifestado pelos ocidentais ancorava-se principalmente no custo da efetivação das disposições do segundo pacto, o qual instituiu os direitos sociais. A solução, para tanto, foi a consagração da teoria da progressividade ou da implementação progressiva de tais direitos, ou seja, os direitos sociais deveriam ser realizados de forma progressiva e na medida do máximo dos recursos disponíveis. 
diversos projetos de lei para a criação generalizada de disciplinas de cunho social ou moral, apenas com o intuito de agregar mérito aos seus currículos. Em estudo realizado sobre a inclusão de disciplinas nos currículos escolares, o Deputado Galvão Vieira (Oliveira, 2009:160) afirma que, se todos os projetos de lei desse conteúdo tivessem sido convertidos em lei, os jovens estudantes estariam sendo obrigados a cursar mais de 30 (trinta) disciplinas (Oliveira, 2009:160), além das que já são previstas na legislação que rege a educação escolar.

E a questão não para por aí. O parlamentares, com o intento de criar essa variedade de disciplinas, trazem o errôneo argumento de que a educação escolar deve ter a capacidade de sanar as mazelas sociais. Com base nesse fato, Rosimar de Fátima Oliveira (Oliveira, 2009:160) tece feroz crítica, dizendo que a escola é percebida, pelos desinformados parlamentares, como a instituição capaz de promover a redenção de uma sociedade em crise, e o meio sugerido para isto é a criação de disciplinas que se voltam fundamentalmente para um conteúdo moral, buscando a formação de valores que, na avaliação dos autores dessas proposições, encontrar-se-iam ausentes na sociedade. E, sem possibilidade de parafrasear suas duras críticas, a educadora continua: «na concepção expressa através dessas proposições, é como se o currículo escolar se compusesse de fora para dentro das escolas, pelo somatório de disciplinas sem necessária conexão entre si (...). Não são preocupações de tais projetos os objetivos precípuos da instituição escolar, mas as próprias problemáticas sociais que os inspiram» (Oliveira, 2009:163).

A par dessas severas críticas, a criação irrefletida de disciplinas curriculares, de fato, não é sadia e profícua ao estudante e, quiçá, não tenha qualquer eficácia para o seu futuro, pois é inegável que os objetivos precípuos da educação, notadamente na sua etapa básica, devem ser a alfabetização, a formação para o trabalho e a conscientização e reflexão para a vida.

Não obstante, pensa-se, a educação formal para o consumo ora proposta é necessária, na medida em que está diretamente relacionada ao exercício típico da cidadania, sendo ato inerente a vida de todos os cidadãos. Esse fato, por si só, faz imprescindível a formação educacional do cidadão para o consumo. E essa educação formal que se propõe não decorre unicamente da vulnerabilidade do consumidor, mas simplesmente da sua qualidade de elemento integrante de uma sociedade de consumo, que necessita ser educado para o consumo, com vistas não apenas a promoção da sua personalidade e felicidade, mas também a harmonização das relações privadas e proteção do meio ambiente para as futuras gerações.

Nesse sentido, defende-se o conteúdo da disciplina curricular com base nos seguintes objetivos: (a) incutir no consumidor o poder de reflexão e o juízo crítico, especialmente, diante das políticas econômicas de incentivo ao consumo e as práticas comerciais dos fornecedores; (b) proteger o consumidor, especialmente, as crianças e adolescentes, diante das armadilhas das ofertas e publicidades; (c) promover a sus- 
tentabilidade e o consumo consciente, com vistas a proteção do meio ambiente para as gerações futuras; e, sobretudo, (d) incutir no espírito de cada consumidor uma nova mentalidade, mais exigente e aguerrida, especialmente, quanto a postulação dos seus direitos, tornando-o um cidadão mais forte e ciente de seus direitos.

Os dois primeiros objetivos - (a) e (b) - estão relacionados às funções defensiva e protetiva dos direitos fundamentais e diz respeito, respectivamente, à proibição de interferência na esfera particular do seu titular, em decorrência de ações do Poder Público ou de sujeitos privados (Hachem,2013:131), bem como na proteção dos direitos fundamentais contra ameaças ou ataques provindos de terceiros (Novais,2010 :86). E, de fato, é inegável que o consumidor, na relação e no mercado de consumo, é constantemente afetado em sua racionalidade, não de forma direta, mas por distorções em sua liberdade de atuação e escolha, provocados, principalmente, pelos seguintes fatos: (a) as práticas comerciais de oferta e publicidade, constantemente renovadas por técnicas cada vez mais bem elaboradas e, em muitas delas, agressivas e superestimuladas aos bens de consumo; (b) o desenvolvimento tecnológico dos computadores e telefones móveis, aliado a melhoria da qualidade dos sinais de internet e a facilitação do acesso do público em geral a esses produtos (computadores e celulares) e serviços (internet); (c) a facilitação na concessão de créditos aos consumidores, «sobretudo a concessão do «dinheiro de plástico» - cartões de crédito - e cheques especiais» (Filomeno, 2015:127), além do crédito consignado em benefício previdenciário e salário e os créditos on line; e, (d) o não cumprimento a contento pelos fornecedores das regras básicas de proteção ao consumidor, especialmente, no que se refere a oferta de preços, regulada pelo Decreto n. 5.903/2006, a qual impõe uma série de regras que não se verifica no dia-a-dia do mercado de consumo.

Não bastassem os fornecedores, o Poder Público também tem o condão de afetar, em determinadas situações, a liberdade de atuação e escolha do consumidor, notadamente, quando promove políticas econômicas de incentivo ao consumo. Em cenário assim, o cidadão fica, absolutamente, impotente e indefeso, como bem esclarece Antônio Carlos Efing (2011:106): «o homem não é nada para além da economia, submetendo-se a ela e às suas leis, não sendo sujeito na economia, não sendo titular de direitos, mas objeto visto que é destinatário sem estatuto dos produtos, moldados à conveniência do mercado» e acrescente-se, também, do Estado.

Apenas a título de exemplificação, nos últimos anos, diante da crise econômica que assolou o país, o Governo Brasileiro editou uma série de leis com o claro intuito de incentivar o consumo e provocar inegáveis distorções na liberdade de atuação e escolha dos consumidores. Assim, citam-se as leis de redução / exclusão do IPI (imposto sobre produtos industrializados), redução da taxa de juros e liberação do FGTS inativo (Fundo de Garantia sobre Tempo de Serviço) (Lei n. 13.446/2017).

As consequências desses fatos - práticas comerciais e políticas econômicas - podem ser drásticas aos consumidores, especialmente, em relação aos carentes de poder 
de reflexão e juízo crítico, resultando fatalmente no superendividamento do cidadão, para citar apenas uma das drásticas consequências. Nesse sentido, Antônio Carlos Efing (2011:327), em artigo em coautoria, menciona que uma das causas desse problema é justamente a falta de educação financeira ou de informações adequadas aos consumidores sobre os impactos das dívidas no seu orçamento. Esse problema não é recente, mas tem ganhado visibilidade em função da grave crise econômica que os países - em especial, o Brasil - enfrentam. Para tanto, alerta Antônio Carlos Efing (2011:325-326), é urgente encontrar soluções e desenvolver políticas públicas não apenas para conter, mas também para prevenir o superendividamento dos consumidores, pois diferentemente do que ocorre com as empresas, que contam com os institutos da falência e da recuperação judicial ou extrajudicial como saída para os seus problemas financeiros, os consumidores superendividados não conseguem discutir suas dívidas de forma clara e em um só procedimento.

O consumidor superendividado é prejudicial à própria economia, pois ele é lançado para fora do mercado de consumo, por conta do seu reduzido ou inexistente poder de compra (Efing,2011:334). E, neste passo, a preparação do consumidor para o consumo por meio da educação, ao contrário do que se possa imaginar, não significa um inibidor a economia, mas ao contrário, representa uma contribuição a uma economia mais saudável, com um maior número de participantes.

Dentre as soluções mais eficazes que se propõe, portanto, está a educação para o consumo, a qual ensejaria, simultaneamente, a garantia e concretização de dois outros imprescindíveis direitos, quais sejam: (a) o direito a liberdade de escolha e (b) o direito à igualdade nas contratações (Cavalieri, 2014:101-102). É certo que, já hoje, o consumidor tem assegurado a liberdade de atuação e de escolha no mercado de consumo, mas somente terá plena liberdade - e consequentemente igualdade -, quando tiver maior poder de reflexão e juízo crítico, pois como diz Hermann Krings et alii, «a liberdade só é possível onde a liberdade se abre a outra liberdade (Hippler, 2010:373). O consumidor, portanto, somente terá plena liberdade, se for dotado de poder de reflexão e juízo crítico, a fim de que possa estar seguro e consciente diante das armadilhas das práticas comerciais e dos incentivos das políticas econômicas.

A educação, afirma Ana Paula de Barcellos (Hippler, 2010:373), é pressuposto básico para a participação do cidadão no âmbito do Estado. E acrescenta ainda, a educação formal é também necessária à transmissão da informação acerca dos direitos mais elementares, como o direito do consumidor, tendo o condão, neste particular, de propiciar a correção de uma série de desvios na racionalidade do consumidor, cumprindo, assim, o quarto objetivo - (d) - do conteúdo da disciplina curricular.

Esse objetivo - (d) - é salutar, ainda, na medida em que o foco da educação brasileira, nos moldes atuais, se concentra mais no desenvolvimento das competências do que dos conhecimentos. A preocupação da política educacional brasileira, na visão da pedagoga Olgaíses Cabral Maués, é «formar pessoas que se adaptem rapidamente 
ao mundo dos negócios, que possam atender às demandas empresariais, que contribuam efetivamente com a produção da mais-valia»(Maués,2009:287), «deixando em segundo plano os conhecimentos e os saberes que permitam a formação de um cidadão capaz de ser sujeito de sua história, construtor de seu destino e capaz de fazer escolhas conscientes e livres» (Maués,2009 :291).

O terceiro objetivo - (c) - relacionado ao conteúdo da disciplina de educação para o consumo estaria voltado a implementação de outro direito fundamental coletivo, qual seja, à proteção do meio ambiente, por meio do consumo sustentável. Nesse sentido, o meio ambiente ecologicamente equilibrado é um bem de uso comum do povo e um direito de todos os cidadãos, estando o Poder Público e a coletividade obrigados a preservá-lo e a defendê-lo, para as presentes e futuras gerações (art. 225 da CRFB).

Sem o intuito de exaurir todos os vieses dessa questão, o que se pretende defender é que o consumo consciente, notadamente, pela redução do desperdício - principalmente de alimentos -, pode, de fato, ser incutido na mentalidade da coletividade por meio da educação. Segundo o consultor do Senado Federal, Marcos Peixoto, um dos problemas do desperdício é a carência de informação e capacitação das pessoas, sendo necessário mecanismos de políticas públicas e campanhas educativas para conscientizar a sociedade desse problema coletivo, mas que afeta a cada um, haja vista a oneração dos produtos para compensar as perdas e o aumento da escassez de alimentos em decorrência dos abusos provocados pelo desperdício (Despedício:2016).

De certo, o desperdício de alimentos pode ocorrer em várias fases da sua manipulação - colheita, armazenagem, transporte, acondicionamento e consumo final - e podem ser atribuíveis a diversos fatores, não apenas ao nível cultural e educacional da população de cada país. Aliás, a proporção do desperdício é igual em países pobres e ricos, variando apenas a etapa em que o desperdício se verifica. Segundo levantamentos da FAO (Organização das Nações Unidas para Alimentação e Agricultura), nos países subdesenvolvidos, as perdas acontecem na colheita e no transporte, ao passo que, nos países desenvolvidos, isso ocorre no consumo final. Tragicamente, no entanto, o Brasil, segundo os técnicos da Embrapa (Empresa Brasileira de Pesquisa Agropecuária), enfrenta esses dois problemas de desperdícios, dependendo da região ou da localidade (Despedício, 2016).

No Brasil, 39 (trinta e nove) mil toneladas de alimentos próprios para o consumo são jogados no lixo todos os dias, sendo 10\% (dez por cento) desse desperdício verificado ao final da cadeia de abastecimento. O percentual é aparentemente baixo, mas as consequências ambientais e econômicas são drásticas, especialmente, com o aumento dos preços dos produtos para compensar as perdas e o aumento da escassez de alimentos. Ainda, esse desperdício é causado por $41 \%$ (quarenta e um por cento) das famílias brasileiras, o que representa um número bastante considerável (Depedício, 2016), a ponto de ser indispensável a política pública nessa seara.

Os resultados dessas pesquisas, aliados às causas do desperdício no consumo, de- 
monstram, enfim, o quanto a educação para o consumo pode ser útil e necessária a proteção e promoção do meio ambiente, notadamente, pela alteração na mentalidade e no comportamento de cada cidadão. Aos Poderes Públicos, portanto, cabe a tarefa de implementar um sistema de ensino qualitativo, ainda que a longo prazo, mas que seja capaz de incutir na mente do cidadão a reflexão necessária para atingir os objetivos ora propostos, o que, aliás, passa-se a discorrer no próximo capítulo.

\section{A formalização da educação para o consumo como disciplina nos currículos escolares: da competência institucional-normativa ao instrumento jurídico- político}

Tecidas as justificativas para a elaboração de uma política pública direcionada a educação formal para o consumo, resta, por último, discutir acerca dos requisitos formais necessários a implementação dessa prestação pública, quais sejam: (a) a competência institucional-normativa para a implementação da educação formal para o consumo em âmbito nacional; e, (b) o instrumento jurídico-político para a implementação da educação formal para o consumo.

Sem maiores delongas, a CRFB atribuiu competência legislativa privativa à União para estabelecer as linhas gerais da educação em âmbito nacional (art. 22, XXIV) - o que o fez, por meio da Lei n. 9.394/1996 (LDBE) - e concorrente aos Estados e ao Distrito Federal para a produção das normas específicas (art. 24, IX) - o que o fez e o fará por meio de leis estaduais e municipais. A LDBE, por sua vez, reforça a atribuição constitucional de organização do sistema de ensino, em regime de colaboração, entre a União, os Estados, o Distrito Federal e os Municípios ( $\operatorname{art.} 8^{\circ}$, caput), estabelecendo privativamente ao ente federal a coordenação da política nacional de educação, articulando os diferentes níveis e sistemas e exercendo função normativa, redistributiva e supletiva em relação às demais instâncias educacionais ( $\left.\operatorname{art.} 8^{\circ}, \S 1^{\circ}\right)$.

A organização do sistema de ensino começa, primordialmente, pela criação de um plano nacional de educação - art. 214 da CRFB e art. $9^{\circ}$, I da LDBE -, que tem o objetivo de articular o sistema nacional de educação, definindo as diretrizes, os objetivos, as metas e as estratégias de implementação para assegurar a manutenção e o desenvolvimento do ensino em seus diversos níveis e etapas. A partir desse plano nacional de educação, a União, em colaboração com os Estados, o Distrito Federal e os Municípios, estabelecerá competências e diretrizes para a educação infantil, o ensino fundamental e o ensino médio, que nortearão os currículos e seus conteúdos mínimos (art. 210 da CRFB e art. $9^{\circ}$, IV da LDBE). Evidentemente, a atuação dos entes estatais, em regime de colaboração, na elaboração de conteúdos curriculares, tem a finalidade de assegurar a mesma formação básica comum a todos os estudantes, mas não impede a criação de outras disciplinas transversais, pelo Distrito Federal, Estados e Municípios, em respeito aos valores culturais e artísticos, nacionais e regionais (Maliska, 2014:1973). 
A base curricular mínima é elaborada pela União, por meio do Conselho Nacional de Educação (CNE), órgão pertencente ao Ministério da Educação (art. $9^{\circ}, \$ 1^{\circ}$ da LDBE). Recentemente, a União reformulou a base curricular do ensino médio, ao que passou a ser denominada de Base Nacional Comum Curricular (BNCC), por meio do art. 35-A da Lei n. 13.415/2017, abrangendo as seguintes disciplinas: (a) linguagem e suas tecnologias; (b) matemática e suas tecnologias; (c) ciências da natureza e suas tecnologias; e, (d) ciências humanas e sociais aplicadas. Esse é, portanto, o conjunto orgânico e progressivo de aprendizagens essenciais que todos os alunos devem, obrigatoriamente, desenvolver ao longo das etapas e modalidades da Educação Básica. E mais, essa base curricular deve orientar os currículos dos sistemas e redes de ensino das Unidades Federativas, como também as propostas pedagógicas de todas as escolas públicas e privadas da educação infantil, ensino fundamental e ensino médio.

A BNCC, como se vê, comporta um conjunto de disciplinas obrigatórias a ser aplicada em todo o sistema da educação nacional. A criação de novos componentes curriculares de caráter obrigatório, além desses já definidos pela BNCC, dependerá de aprovação do CNE e homologação pelo Ministro da Educação, como estabelece o $\$ 10$, do art. 26 da LDBE, competência esta definida recentemente pela Lei n. $13.415 / 2017$.

Dessa breve análise constitucional e legal, constata-se que a elaboração da base curricular e a criação de novas disciplinas obrigatórias fica a cargo de autorização do Poder Executivo, mas precisamente do Ministério da Educação, por meio do seu $\mathrm{CNE}$, não podendo ser atribuível, em essência, aos parlamentares, sob pena de se caracterizar um vício de iniciativa.

Esse, aliás, é o entendimento do Deputado João Matos (Oliveira,2009:166), ao afirmar que, do ponto de vista estritamente legal, a definição de disciplinas no currículo escolar dos ensinos fundamental e médio é da competência do Ministério da Educação, ouvido o CNE. E complementa que, não é da competência do Legislativo Federal a elaboração de proposições que venham a incluir novas disciplinas, em nível nacional, no currículo escolar de quaisquer níveis de ensino.

Nesse sentido, Rosimar de Fátima Oliveira(Oliveira, 2009:164) entende que a instituição dessas disciplinas não pode ser feita por meio de lei de inciativa de parlamentares, mas sim por meio de lei que emende a própria LDBE, de iniciativa das próprias escolas, de suas comunidades - trata-se da chamada gestão democrática da escola, com a participação da sociedade (Maliska,2014 :1968) (art. 205 da CRFB) - e dos Conselhos de Educação, com a orientação do Ministério da Educação.

De fato, as incontáveis proposições legislativas para a criação de novas disciplinas por parlamentares não podem ser admitidas e já foram objeto de crítica no tópico n. 3.2., por uma série de razões, especialmente: (a) pelo elevado número de disciplinas curriculares que se pretende impor aos estudantes; (b) pelo despreparo técnico e científico dos parlamentares; e, (c) pela criação de disciplinas preocupadas em corri- 
gir problemas sociais e não em desenvolver a personalidade e a cidadania do estudante, bem como a conscientização e a reflexão.

Desta forma, a inclusão da matéria de educação para o consumo que ora se propõe, deverá ser feita, por meio de reforma da própria LDBE, obedecidos aos requisitos, estabelecidos em Nota Técnica, pelo consultor legislativo da Câmara dos Deputados, José Maria G. de Almeida Júnior (2003:3-4), quais sejam: (a) sólida fundamentação doutrinária e legal da Comissão de Educação, Cultura e Desporto; (b) argumentos técnico-pedagógicos e em disposições constitucionais e infraconstitucionais, sobretudo da LDBE; e, (c) referenciais definidos pelos parâmetros curriculares nacionais elaborados pelo Ministério da Educação e discutidos pelos Conselhos de educação em conjunto com as escolas e suas comunidades.

No mesmo sentido, Vera Hippler (2010:363) reforça que tais matérias devem ser abordadas pelos Parâmetros Curriculares Nacionais, sendo de competência da Câmara de Educação Básica tal iniciativa (Lei n. 9.131/1995, art. $9^{\circ}, \$ 1^{\circ}$, «C»), todavia, devem estar sempre em consonância com as diretrizes emanadas do CNE (LDBE, art. $9^{\circ}, S_{1}^{\circ}$ ) e dos conselhos dos Estados e Municípios, que, por sua vez, sujeitam-se a todos aos parâmetros constitucionais e legais antes elencados.

Desta forma, a criação de novas matérias obrigatórias - como é o caso da educação para o consumo -, somente será possível por lei que emende a própria LDBE. Na história recente da educação brasileira, a LDBE, no que se refere a inclusão de novas disciplinas curriculares, já foi modificada, desde a sua edição, em três oportunidades apenas: (a) pela Lei n. 9.475/97 para a criação da disciplina de ensino religiosos, nas escolas de ensino fundamental; (b) pela Lei n. 10.328/2001 para a criação da disciplina de educação física, nos currículos dos ensinos fundamental e médio; (c) pela Lei n. 10.639/2003 para a criação da disciplina de História e Cultura Afro-brasileira, nos estabelecimentos de ensino fundamental e médio. Em todas essas modificações foram utilizadas as mesmas regras procedimentais, notadamente, no que se refere a competência institucional-normativa (Oliveira, 2009:115-125).

Por fim, é, sem dúvida, no ensino fundamental da Educação Básica que a disciplina de educação para o consumo adquirirá maior eficácia e efetividade e produzirá melhores efeitos, haja vista a obrigatoriedade da educação nesse nível de ensino e a formação do caráter e transformação da mentalidade do estudante em cidadã, cumprindo, assim, fielmente com o desenvolvimento da sua capacidade de aprender, com domínio da leitura, escrita e cálculo; da sua compreensão do ambiente natural e social, do sistema político, da tecnologia, das artes e dos valores que fundamentam a sociedade; da sua capacidade de aprendizagem; e, do seu fortalecimento dos vínculos de família, dos laços de solidariedade humana e tolerância recíproca em que se assenta a vida social, objetivos esses traçados pelo art. 32 da LDBE. 


\section{Conclusões}

(a) Os Direitos Fundamentais estão submetidos a um regime jurídico especial, que tem por fundamento a realização da dignidade da pessoa humana em seu grau máximo. É, a partir desse regime diferenciado que se permite fundamentar a proposta do presente artigo, qual seja, a elaboração de uma disciplina de educação formal para o consumo, direcionada ao ensino fundamental, tendo em vista a concretização integral do direito fundamental de defesa do consumidor, por meio da garantia da sua ampla liberdade de atuação e escolha no mercado de consumo, bem como a implementação de outros direitos fundamentais sociais e coletivos, pela conscientização do consumo e consequente proteção ao meio ambiente.

(b) A previsão constitucional da defesa do consumidor como princípio da ordem econômica, ao lado de outros princípios, como a livre-iniciativa, a propriedade privada e a livre-concorrência, acarreta uma proteção insuficiente do consumidor, notadamente, porque a tutela do consumidor se limita a reparabilidade da ilicitude e da abusividade, não sendo o consumidor tutelado preventivamente.

(c) A necessidade de uma proteção preventiva do consumidor, por meio da sua educação, é necessária diante da constatação de vários fatores sociais, políticos e econômicos que massacram o consumidor no dia-a-dia do mercado de consumo, principalmente, pelas práticas comerciais cada vez mais bem elaboradas e ocultas, inclusive, com o auxílio das redes sociais, a participação efetiva e direta das crianças e adolescentes na aquisição de produtos e serviços para as famílias, as políticas econômicas de incentivo ao consumo com o intuito de alavancar a econômica de mercado e a política educacional ineficiente e voltada para o desenvolvimento de competências típicas para o trabalho e o consumo no mercado, sem se preocupar com o desenvolvimento do poder de reflexão e do juízo crítico do estudante.

(d) A educação para o consumo seria, portanto, premissa básica para incutir no consumidor uma mudança de mentalidade e de comportamento. É inegável, diante dos fatos apontados e da vulnerabilidade do consumidor no mercado de consumo, a sua necessidade de ser dotado de um poder de reflexão e de um juízo crítico, a fim não apenas de protegê-lo contra as armadilhas do mercado - decorrentes das práticas comerciais e das políticas econômicas -, mas também conscientizá-lo acerca do consumo moderado para proteção do meio ambiente contra a escassez de recursos, ocasionados especialmente pelo desperdício no consumo.

(e) Por último, propôs-se no presente artigo, a instituição da educação para o consumo como matéria integrante da base nacional curricular, devendo ser ministrada a todos os estudantes do ensino fundamental da Educação Básica (crianças e adolescentes dos 7 (sete) até os 15 (quinze) anos), cuja implementação deve ser feita por lei de iniciativa das próprias escolas, de suas comunidades - trata-se da chamada gestão democrática da escola, com a participação da sociedade (art. 205 da CRFB) - e 
dos Conselhos de Educação, com a orientação do Ministério da Educação, mediante reforma / emenda da LDBE.

\section{Referências}

Aizpurua, Alaitz, Izarne Lizaso, and Idoia Iturbe (2018). «Learning Strategies and Reasoning Skills of University Students.» Revista de Psicodidáctica (English ed.) 23 (2):110-116

Alexy, Robert (2015). Teoria dos Direitos Fundamentais. 2. ed. São Paulo: Malheiros.

Almeida Junior, José Maria (2003). <Proposições sobre a criação de disciplinas escolares e atividades curriculares $>$. Nota Técnica. Brasília: Consultoria Legislativa / Câmara dos Deputados.

Aleix, Cristina Fuertes-Planas (2013). «Cultura y transmisión de los derechos humanos.» Estudios sobre el Mensaje Periodistico 19: 187-195.

Aristizabal-Almanza, Johanna Lorena, Arcelia Ramos-Monobe, and Violeta Chirino-Barceló.(2018) «Active Learning to Develop Motor Skills and Teamwork.» Revista Electrónica Educare 22 (1): 319-344.

AzPitarte SÁnChez, Miguel (2017). «National Identity and the European Court Legitimacy.» Teoria y Realidad Constitucional 39, 1: 413-48.

Barcellos, Ana Paula de (2008). A eficácia jurídica dos princípios constitucionais o princípio da dignidade da pessoa humana. 2. ed. Rio de Janeiro: Renovar.

-. (2010). «Constitucionalização das políticas públicas em matéria de direitos fundamentais: o controle político-social e o controle jurídico no espaço democrático». in Sarlet, Ingo Wolfgang; Timm, Luciano Benetti. Direitos Fundamentais: orçamento e reserva do possível. Porto Alegre: Livraria do Advogado: 101-132.

Biglino Campos, Paloma (2017). "Crisis of representation, legitimacy of exercise and types of resposability.» Revista de Derecho Politico 100: 481-511.

Briede Westermeyer, Juan, Isabel Leal-Figueroa, and Cristhian Pérez-Villalobos (2018). «Análisis de Referentes como Estrategia de Aprendizaje del Diseño Conceptual de Productos.» Formación universitaria 11 (1): 3-12.

Bucci, Maria Paula Dallari (2006). Direito Administrativo e Políticas Públicas. São Paulo: Saraiva.

-. (2006). «O conceito de política pública em direito». In Bucci, Maria Paula Dallari (organizadora). Políticas Públicas: reflexões sobre o conceito jurídico. São Paulo: Saraiva: $1-49$.

CAstro, Jorge Abrahão de (2011). «Política social no Brasil: marco conceitual e análise da ampliação do escopo, escala e gasto público». Revista Brasileira de Monitoramento e Avaliação, Porto Alegre,1: 66-95.

Cavalieri Filho, Sergio (2014). Programa de Direito do Consumidor. 4. ed. São Paulo: Atlas. 
Despedício de Alimentos (2016). Revista Em Discussão. Brasília: Senado Federal, ano 7, 30, dezembro: 22-34.

De Mello Massimino, Daniel, and Danielle Anne Pamplona (2015). ««Saberes» de Morin na Educação Jurídica: Caminhos à Educação para o Desenvolvimento Sustentável.» Opción 31(3): 446-469

EfIng, Antônio Carlos; Polewka, Gabriele; Oyague, Olenka Woolcott (2011). «A crise econômica brasileira e o superendividamento da população: emergência do aprimoramento legislativo para a tutela social». In Marques, Cláudia Lima; Gsell, Beate (organizadoras) (2015). Novas tendências do Direito do Consumidor. São Paulo: Revista dos Tribunais: 325-369.

-. (2011). «Direito do Consumo e Direito do Consumidor: reflexões oportunas». Revista Luso-Brasileira de Direito do Consumo. Brasília, 1(1): 103-120.

Elgueta Rosas, María Francisca and Eric Eduardo Palma González (2014). «A Proposed Classification of the Master Class at the Faculty of Law.» Revista Chilena de Derecho. 41, 3: 907-924

Embid Irujo, Antonio (2008). "Citizenship Education in the Spanish Education System. Legal Reflections.» Revista Espanola de Derecho Constitucional 28, (83): 11-56.

FARIA, Júlio Herman (2009). «Políticas Públicas: o diálogo entre o político e o jurídico». A\&C Revista de Direito Administrativo \& Constitucional, Belo Horizonte, 9 (35): 157-169.

Filomeno, José Geraldo Brito (2015). Manual de Direitos do Consumidor. 13. ed. São Paulo: Atlas.

Flores Rivas, Juan Carlos (2014). «Right to Education. Its Essential Content in the Chilean Law.» Estudios Constitucionales 12 (2): 109-36

Fuertes-Planas Aleix, Cristina (2013). «Culture and Transmission of Human Rights.» Estudios Sobre el Mensaje Periodistico 19: 187-95.

Gabardo, Emerson (2009). Interesse Público e Subsidiariedade. Belo Horizonte: Fórum.

Ganga Contreras, Francisco; Juan Abello Romero; Erwin Navarrete \& Valdivieso, Patricio. (2013). «Perceptions of Regulatory Frameworks for Higher Education, by Rectors and Maximum Collegiate Bodies of Chilean Universities». Argos, 30(59):107-135.

GonZÁLEz Galván, Jorge Alberto (2013). «Legal Education, Research and Intelligents Human Rights.» Boletin Mexicano de Derecho Comparado, 137: 499-527.

-. (2012). «The Pedagogical Constructivism Applied to Law: Towards a Dynamic Formation.» Boletin Mexicano de Derecho Comparado, 133: 119-39.

Gómez Pinto, Luis Ricardo (2014) «Public Policy in Education as a Factor of Economic Development: The Economic Tension between Development Model and Growth Model (I).» Vniversitas 128 (2014): 121-52. 
Hachem, Daniel Wunder (2013). «A dupla titularidade (individual e transindividual) dos direitos fundamentais econômicos, sociais, culturais e ambientais». Revista de Direitos Fundamentais e Democracia, Curitiba, 14 (14); 618-688.

-. (2014). «Direito fundamental ao serviço público adequado e capacidade econômica do cidadão: repensando a universalidade do acesso à luz da igualdade material». A\&C - Revista de Direito Administrativo \& Constitucional, Belo Horizonte, 14 (55): 123-158.

-. (2014). Tutela administrativa efetiva dos direitos fundamentais sociais: por uma implementação espontânea, integral e igualitária. Curitiba, $614 \mathrm{f}$. Tese (Doutorado) - Programa de Pós-graduação em Direito, Universidade Federal do Paraná.

Hernádez, Del Salto, Victor; Victor Hernandez del Toro, Susana Arias, and C. H. Toro. (2017) «A Model of Identification and Adaptation of Learning Styles Based on Cognitive Inference.» Paper presented at the Proceedings of IEEE International Conference on Teaching, Assessment and Learning for Engineering, TALE.

HipPleR, Vera (2010). "A relação educacional como relação especial de sujeição (RES) e os limites à liberdade de ensinar dos professores nas instituições públicas de ensino». In Sparapani,

Illera Lobo, Mercedes Leonor (2017). «Relationship of Theory and Practice in the Teaching of Law.» Espacios 38 (45).

JimÉnez, Lucía., Alfonso Javier García, Javier López-Cepero, and Francisco Javier Saavedra (2018). «The Brief-Acra Scale on Learning Strategies for University Students.» Revista de Psicodidactica 23 (1): 63-69.

López, Pablo Nuevo (2014). «Derechos Fundamentales E Ideario Educativo Constitucional.» Revista de Derecho Politico 89: 205-38.

Sparapani,Priscila;, Renata Porto Adri (2010). Intervenção do Estado no Domínio Econômico e no Domínio Social. Belo Horizonte: Forum: 351-396.

Maliska, Marcos Augusto (2014). «Art. 208 da Constituição da República». In Canotilho, Gomes; Mendes, Gilmar Ferreira; Sarlet, Ingo Wolfgang; Steck, Lenio Luiz. Comentários à Constituição do Brasil. São Paulo: Saraiva.

MAUÉs, Olgaíses Cabral (2009). «O papel da escola na construção dos saberes e os limites da noção de competências». In: Ferreira, Eliza Bartolozzi; Oliveira, Dalila Andrade (organizadoras). Crise da escola e políticas educativas. Belo Horizonte: Autêntica: 287-307.

Montoya, Juny (2010). «The Current State of Legal Education Reform in Latin America: A Critical Appraisal.» Journal of Legal Education 59 (4): 545-66.

Netro, Luísa Cristina Pinto (2009). Os direitos sociais como limites materiais à revisão constitucional. Salvador: JusPodivm.

Nogueira Alcalá, Humberto (2008). «El derecho a la educación y sus regulaciones básicas en el derecho constitucional chileno e internacional de los derechos humanos.» Ius et praxis 14.(2): 209-269. 
NovaIs, Jorge Reis (2010). As restrições aos Direitos Fundamentais não expressamente autorizadas pela Constituição. 2. ed. Coimbra: Coimbra Editora.

Oliveira, Rosimar de Fátima (2009). Políticas educacionais no Brasil - qual o papel do Poder Legislativo? Curitiba: Protexto.

Prado, Carlos Vidal (2017). «El diseño constitucional de los derechos educativos ante los retos presentes y futuros//The constitutional design of educational rights to the present and future challenges.» Revista de Derecho Político 100: 739-766.

Pérez Perdomo, Rogelio (2018).. «From Harvard to Stanford. On the History of the Legal Education of United States.» Boletin Mexicano de Derecho Comparado 50 (151): 313-358

Rodríguez Patrón, Patricia (2017). «Singular Law as Jurisprudential Category: A New Approach to Its Particular Meaning and Problems.» Revista de Derecho Politico, 99: 167-197.

Ruiz- Rico Ruiz, Gerardo (2017). «The Territorial Development of the Social Constitution.» Revista de Derecho Politico, 100: 799-829.

Salazar Benitez, Octavio (2016). «Single-Sex Education and Right to Education about the Unconstitutionality on Article 84.3 Reform of the Organic Law of Education.» Revista Española de Derecho Constitucional 36 (106): 451-478.

SARLET, Ingo Wolfgang (2007). "A influência dos direitos fundamentais no direito privado: o caso brasileiro». In Monteiro, Antonio Pinto; Neuner, Jörg; SARLET, Ingo Wolfgang (2007). Direitos Fundamentais e o Direito Privado - Uma Perspectiva de Direito Comparado. Coimbra: Almedina: 111-144.

Sgarbossa, Luis Fernando (2010). Crítica à Teoria dos Custos dos Direitos: Reserva do Possível. V. 1. Porto Alegre: Sergio Antonio Fabris Editor.

Shier, Paulo Ricardo; Shier, Adriana da Costa Ricardo (2016). Serviço público adequado e a cláusula de proibição de retrocesso social. In: Revista de Direito da Administração Pública. Niterói, ano 02 (1): 204-223.

Silva, José Afonso da (2014). Teoria do Conhecimento Constitucional. São Paulo: Malheiros.

VAlLe, Vanice Regina Lírio do (2009). Políticas públicas, direitos fundamentais e controle judicial. Belo Horizonte: Fórum.

Zuñiga Urbina, Francisco (2014). «New Constitution and Constituent Assembly in Chile.» Revista de Derecho Politico 91: 341-57.

\section{Sobre o autor}

Doutorando em Direito Econômico pela Pontifícia Universidade Católica do Paraná (PR); Mestre em Direito Negocial pela Universidade Estadual de Londrina (PR); Bacharel em Direito pela Universidade Estadual de Maringá (PR). Professor Efetivo 
0 DIREITO FUNDAMENTAL A EDUCAÇÃO FORMAL PARA O CONSUMO COMO MEIO DE CONCRETIZAÇÃO

na Universidade Estadual de Maringá (PR). Advogado no Estado do Paraná. E-mail: edsonmitsuo@yahoo.com.br. 